REFERENCES:

[1] Felson DT. The epidemiology of knee osteoarthritis: results from the Framingham Osteoarthritis Study. Semin Arthritis Rheum, 1990; 20(3 Suppl 1): 42-50.

[2] Parazzini F. Progretto Menopausa Italia Study Group Menopausal status, hormone replacement therapy use and risk of self-reported physician-diagnosed osteoarthritis in women attending menopause clinics in Italy. Maturitas, 2003; 20 (46): 207-12.

Disclosure of Interest: None declared

DOI: 10.1136/annrheumdis-2018-eular.6325

\section{AB1426-HPR IMPLEMENTATION OF NURSE LED CLINIC IN RHEUMATOLOGY DEPARTMENT LJUBLJANA, SLOVENIA}

D Stanković, M. Pavič Nikolič, A. Antonič Zakojč. Department of Rhematology, University Medical Centre Ljubljana, Ljubljana, Slovenia

Background: Nurse-led clinics in Rheumatology Department in Ljubljana have been established in September 2011 after nurses finished education module. The main goal was to provide good care and improved monitoring of patients with rheumatoid arthritis, psoriatic arthritis and ankylosing spondylitis which are treated with biologics. In this way nurses started to contribute and shape new ways in helping patients to better manage their disease. With this new approach the nurses have applied some of the recommendations regarding the role of the nurse in treatment of patients with inflammatory rheumatic diseases.

Objectives: The aim of this study is to describe the organisation, purposes and activities of a nurse-led rheumatology clinics.

Methods: Nurse's intervention data was collected from January 2012 to December 2017. The data is allocated according to individual intervention which has been implemented. We used excel table to represent data.

Results: The patients have opportunity for telephone counselling with the dedicated nurse about issues with their anti-TNF therapies. Between January 2013 and May 2014 we collected data in which we recorded 101 calls from patients who were seeking information about biologics. We recorded how many patients had come to the nurse led-clinics. We sorted them in four groups; nurse led follow up clinics, education about self-administration of biologics or some other medicine, blood or skin tests and daily care unite (table 1).

\begin{tabular}{lcccccc} 
Abstract AB1426HPR & - Table 1. Number of patients after intervention \\
\hline $\begin{array}{l}\text { Intervention/ } \\
\text { Year }\end{array}$ & $\mathbf{2 0 1 2}$ & $\mathbf{2 0 1 3}$ & $\mathbf{2 0 1 4}$ & $\mathbf{2 0 1 5}$ & $\mathbf{2 0 1 6}$ & $\mathbf{2 0 1 7}$ \\
\hline $\begin{array}{l}\text { Nurse led } \\
\text { follow up }\end{array}$ & 478 & 780 & 1009 & 1101 & 1303 & 1455 \\
$\begin{array}{l}\text { Education } \\
\begin{array}{l}\text { Other } \\
\text { intervention }\end{array}\end{array}$ & 74 & 117 & 153 & 130 & 141 & 156 \\
\begin{tabular}{l} 
Daily care unit \\
\hline
\end{tabular} & 265 & 316 & 374 & 395 & 448 & 476 \\
\end{tabular}

Conclusions: The number of interventions has increased and show importance of nurses in patient management. This is most evident in the area of patient education and monitoring.

Disclosure of Interest: None declared

DOI: 10.1136/annrheumdis-2018-eular.5206

\section{AB1427-HPR THE ROLE OF PARENTS' AWARENESS IN PHYSICAL ACTIVITY IN CHILDREN WITH JUVENILE IDIOPATHIC ARTHRITIS}

B. Monek ${ }^{1}$, D Vitár ${ }^{2}$, R. Chrobot ${ }^{3}$, I. Orbán ${ }^{4}$, E. Kiss ${ }^{2}$, G. Poór ${ }^{1} .{ }^{1}$ Rheumatology; ${ }^{2}$ Clinical Immunology, Adults' and Children's Rheumatology, National Institute of Rheumatology and Physiotherapy; ${ }^{3}$ Semmelweis University; ${ }^{4}$ Clincal Immunology, Adults' and Children's Rheumatology, National Institute of Rheumatology and Physiotherapy, Budapest, Hungary

Background: Whilst Juvenile Idiopathic Arthritis (JIA) is one of the most common chronic diseases amongst children, the impact of physical therapy on affected children's life-quality and the importance of an appropriate and regular physical activity get less attention than they ought to. In addition, there are no such studies about the role of parents' awareness in connexion with the regular physical activity for children with JIA available yet.
Objectives: The purpose of the survey was to evaluate the awareness of parents in connexion with the Juvenile Idiopathic Arthritis' diagnose, its treatment options, the importance of regular physical activity and how it affects children's life-quality. Everyday experiences say that children with JIA take part in less physical activities than their healthy mates do. Ou aim was to detect how important regular physical activity is for parents.

Methods: This is a descriptive analysis of our self-compiled questionnaire which has 41 questions. It is being filled in both online and in paper forms since the February of 2017 in the National Institute of Rheumatology and Physiotherapy on the Department of Clinical Immunology, Adults and Children's Rheumatology. Participants of the study are parents whose child has the diagnose of Juvenile Idiopathic Arthritis and ages between 2-18. Parents whose child has not differentiated diagnose or is under 2 years are excluded.

Results: 48 answers met the criteria, 6 answer sheets were excluded. In case the children's condition get worse, $20,8 \%$ of parents marked wrong parental measures. All parents acknowledge the importance of physical activity, but only $63 \%$ of children do regular physiotherapy at home. Parents could not choose from or rank the appropriate and useful ways of physical activities. Beside the medical team (doctor, physiotherapist, nurse) parents get information from media and internet. They would like to get further information personally in words, in written forms or pamphlets. Parents of children with JIA miss psychic support, alternative treatment options and customised, complex information from the general treatment.

Conclusions: The findings of this study support the fact that parents of children with Juvenile Idiopathic Arthritis are well informed about the JIA's inflammatory nature and its symptoms, but they have few and wrong information in connexion with regular physical activity. They have a lack of knowledge about the different kinds of physical activities and sports' effects on the disease, due to which they choose ergonomically wrong kinds of activities in schools or pre-schools. Based on our results, we would like to develop a complex educational program including physical therapy as well.

\section{REFERENCES:}

[1] K Barut, A Adrovic, S Şahin, Ö Kasapçopur. Juvenile Idiopathic Arthritis Balkan Med J. 2017 Mar; 34(2): 90-101.

Disclosure of Interest: None declared

DOI: 10.1136/annrheumdis-2018-eular.5362

\section{AB1428-HPR TWO-YEAR FOLLOW-UP OF THE THERAPEUTIC EXERCISE PROGRAM FOR PATIENTS WITH ROTATOR CUFF TENDINOPATHY: A SINGLE GROUP STUDY TO INVESTIGATE THE EFFECTS ON PAIN AND DISABILITY}

E Turgut, I. Duzgun. Physiotherapy and Rehabilitation, Hacettepe University, Ankara, Turkey

Background: Although exercise training is accepted as one of the important and active treatment approach for the shoulder-related musculoskeletal problems, ${ }^{1}$ the scientific rationale and long-term results for the inclusion of specific progressive exercises are less clear.

Objectives: This longitudinal, single group study aims to investigate the effects of a therapeutic exercise program on pain and disability in patients with the rotator cuff tendinopathy.

Methods: Twenty-eight participants with chronic non-traumatic unilateral shoulder pain diagnosed with rotator cuff tendinopathy (28.6 \pm 5.4 years old, symptoms duration $3.2 \pm 1.5$ months) were included. The appropriate patient education and criteria-based, supervised exercise program including scapular and rotator cuff neuromuscular control exercises were performed. We evaluated self-reported shoulder pain and disability status by using Shoulder Pain and Disability Index (SPADI) $)^{2}$ at baseline, after 6 week, 12 week training, at one-year-follow-up, and two-year-follow-up. Repeated measures ANOVA used for statistical analysis.

Results: Comparisons showed that there was significantly less SPADIpain and SPADI-disability score reported starting from six-week after baseline and at two-year-follow-up $(p<0.05)$.

Conclusions: The findings of the study showed that pain and disability gains can be achieved with 6 week progressive exercise training for participants with rotator cuff tendinopathy. Therefore, the progressive exercise training should be recommended to apply starting from early shoulder rehabilitation program. 